\title{
USING POKA-YOKE METHODS TO IMPROVE EMPLOYMENT POTENTIAL OF INTELLECTUALLY DISABLED WORKERS
}

\author{
N.F. Treurnicht ${ }^{1}$, M.M. Blanckenberg ${ }^{2}$ and H.G. van Niekerk ${ }^{3}$ \\ ${ }^{1,3}$ Department of Industrial Engineering \\ University of Stellenbosch, South Africa \\ nicotr@sun.ac.za, hgvniekerk@gmail.com \\ ${ }^{2}$ Department of Electrical and Electronic Engineering \\ University of Stellenbosch, South Africa \\ mike@sun.ac.za
}

\begin{abstract}
In this project an electronic manufacturing process, namely ribbon cable assembly, was adapted for execution by intellectually disabled individuals. To make the work accessible to them, human error was controlled by a Poka-yoke approach. The design of the work process used industry standard tooling. Mistake-proofing design identified possible errors, and introduced mechanisms and tests that enabled the worker to avoid them. Test results were analysed using learning theory. It is concluded that intellectually disabled individuals can be enabled to perform the task within normal variation compared with a minimum task time, by using the Poka-yoke approach. Selection, however, is desirable.
\end{abstract}

\section{OPSOMMING}

'n Elektroniese vervaardigingsproses, naamlik platkabelsamestelling, word aangepas vir uitvoering deur intellektueel gestremde persone. Vir toeganklikheid deur hierdie groep, word menslike foute beheer deur die Poka-yoke-benadering. Die ontwerp van die werkproses maak gebruik van standaard nywerheidgereedskap. Die ontwerp fokus daarop om die moontlikheid van foute te identifiseer en kenmerke, meganismes, en toetsapparaat te inkorporeer om die voorkoms daarvan onmoontlik te maak. Toetsresultate word ontleed met leerteorie. Die slotsom is dat intellektueel gestremde persone bemagtig kan word, met die Poka-yoke-benadering, om hierdie taak uit te voer binne normale variasie vergeleke met die minimum taaktyd. Keuring is wel wenslik. 


\section{INTRODUCTION}

According to the 2001 census, there were 2,255,982 disabled persons in South Africa, of whom $82 \%$ were unemployed and 279,094 were classified as intellectually disabled [1]. In the developing world, state funding for institutions caring for these individuals - either residentially or as a day care centre - is limited. Contract work performed by these institutions to supplement their funds is limited to non-industrial tasks, such as packaging and recycling. From a human perspective these individuals react positively to opportunities to do productive work, as it strengthens their perception of self-value. These two factors financial need and the human need to do normal things - come together in the research question that was addressed in this study: Are techniques available specifically to design work environments for selected modern high technology production tasks that will enable intellectually disabled individuals to be offered employment?

The work process chosen for investigation in this study is ribbon cable assembly. The work design technique employed is the Japanese Poka-yoke approach. The work station designed as part of the work was evaluated using intellectually disabled individuals. Their performance was assessed with learning theory, and a conclusion was reached.

\section{BACKGROUND}

Ribbon cables are extensively used to interconnect electronic subsystems, such as between the processor board and internal peripheral devices in a computer. The length and number of conductors are the most prominent variables when a ribbon cable is specified. The work station in this study can accommodate variable lengths, and could be adjusted with little effort to accommodate a variable number of conductors.

This study belongs in the broader field of engineering psychology. According to Poulten [2], "The aim of engineering psychology is not simply to compare two possible designs for a piece of equipment, but to specify the capacities and limitations of the human from which the choice of a better design should be deducible". Engineering psychology is thus concerned with adapting equipment and the environment to humans, based upon their psychological capacities and limitations. The above-mentioned definition closely describes the content of the project. An important further point is made by Wickens \& Hollands [3]: "although research topics in engineering psychology are selected because of applied needs, the research goes beyond specific one-time applications and has the broader objective of providing a usable theory on human performance". This last statement corresponds with the objectives of the project: to prove that persons with intellectual disability can perform contemporary technological assembly work, provided that the work environment is designed to accommodate the target worker group, e.g. by means of the Poka-yoke approach.

The term 'Poka-yoke' originated in the period after World War II, when there was a considered effort in Japan to improve quality in order to capture world markets. The term can be directly translated as 'mistake-proofing'. The concept refers to an acceptance that human error is bound to occur; but the Poka-yoke approach to process design makes errors impossible - or at least warns the worker that an error is occurring. Shigeo Shingo pioneered the concept as part of the Toyota production system when serving as an industrial engineer and quality assurance expert [4], [3]. The Toyota production system has since become known as Just In Time (JIT), and has been adopted in several variations of the same core principles such as Lean Manufacturing and Theory of Constraints. The term Poka-yoke is derived from the Japanese word for avoidance (yokeru) of non-deliberate errors (poka). The subsequent 'zero defect' movement embraced the Poka-yoke approach as part of 'quality at source', replacing most post-manufacturing inspection with worker selfinspection [5]. Originally the term used was 'Baka-yoke', which literally meant 'fool proofing'. It was later replaced by 'Poka-yoke', which is less offensive [4]. 
In general practice, Poka-yoke implementations include [6]:

- $\quad$ Location devices (e.g. guide pins in different patterns and/or sizes)

- $\quad$ Error identification and warning systems

- Limit switches

- Counters

- Checklists

The work station in this project makes use of various location devices, and tests with logical 'go/no-go' outcomes.

The target worker group comprises residents of Horizon House, a residential care centre and protective workplace in Stellenbosch. The house primarily accommodates adults who are intellectually disabled, but residents may also have emotional and physical disabilities. Horizon House was established in 1974, and currently care is provided for 103 intellectually impaired adults, 89 of whom live on the premises. Horizon House is partly funded by the State and partly by residents' relatives. Further funds come from fundraisers and supporters of the institution. Contract work could provide valuable supplementary income.

Intellectually disabled individuals, just like people without the disability, experience a full range of human emotions and desire a similar range of life experiences. Although the intellectually impaired learn and develop more slowly than others, they are also able to learn to adapt to new situations and to enjoy life fulfilment. Meaningful employment for disabled individuals can link them into the fabric of society and enhance their sense of worth [7].

To address the research challenge, a work station within advanced technology manufacturing was designed using the Poka-yoke approach. If this could be shown to be successful, it would improve the employment potential of intellectually disabled individuals in South Africa.

\section{DESIGN}

The work station is designed for the assembly of 10-way ribbon cables of various lengths that are used in a table grape packaging unit comprising an electronic scale, a microcontroller, and an array of light emitting diodes (LEDs). This unit is manufactured in South Africa by a small specialist enterprise using make-to-order manufacturing. This type of enterprise has neither large consistent manufacturing volumes nor own facilities. Contract manufacture is therefore logical.

\subsection{Family of products targeted for the work station}

Figure 1(a) shows an insulation displacement connector before assembly. The assembled connector is shown on the right of Figure $1(\mathrm{~b})$. The illustration on the left side of Figure 1 (b) shows the connector with the clamping cover removed to show the insulation displacement connection mechanism.

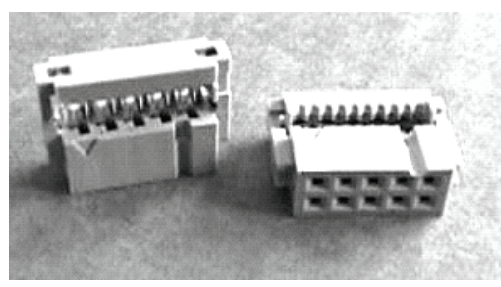

(a) Insulation displacement connectors

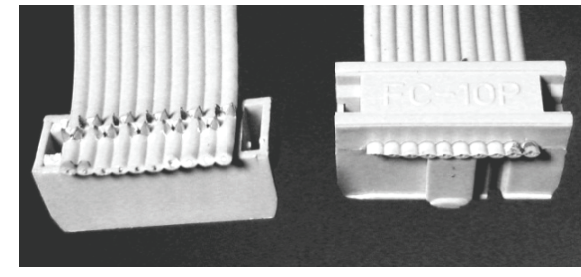

(b) Assembled cable and connectors

Figure 1: Ribbon cable and insulation displacement connectors 
During assembly the clamping cover and the cable underneath are pressed down on to the connector to force the connecting 'blades' through the insulation, making contact with the conductors. The respective 'blades' correspond to the receptacles in the socket (pin 1 to conductor 1).

Ribbon cables are assembled in a set required for each grape packaging unit. Each unit requires a set of 30 cables:

$\begin{array}{ll}- & 20 \times 130 \mathrm{~mm} \\ - & 2 \times 150 \mathrm{~mm} \\ - & 4 \times 280 \mathrm{~mm} \\ - & 4 \times 440 \mathrm{~mm}\end{array}$

The design of the jig should therefore accommodate the four required lengths of cable for the completion of a set.

\subsection{Errors common to this type of assembly}

For a Poka-yoke approach, mistake-proofing is the goal. When designing mistake-proofing mechanisms, all errors or mistakes that can occur need to be identified. The following errors may occur.

\subsubsection{Socket alignment error}

The socket can be mounted with a 180-degree error on the cable. A 180-degree misalignment in the horizontal plane - i.e. left/right misalignment - is an error. A misalignment in the vertical plane - i.e. upside down assembly - is also an error.

\subsubsection{Angular alignment of socket on cable error}

The socket can be mounted with a relatively small angular alignment error on the cable. If the socket is not mounted at a $90^{\circ}$ angle, a short circuit between two conductors may be caused.

\subsubsection{Length of cable error}

The cable can be cut to the incorrect length.

\subsubsection{Cable alignment error}

Cable conductor 1 could be misaligned to socket pin1. The cable can be upside down or misaligned left to right, resulting in misalignment. The cable colour code indentifies conductor 1.

\subsubsection{Crimping error}

If the press is incorrectly operated, or if the locking plate of the IDC connector is omitted, the blades will not penetrate the insulation, resulting in incomplete electrical connection.

\subsubsection{Cutting error}

If the scissors are operated incorrectly, the cutting action does not result in a clean cut, causing frayed strands. These may in turn cause short circuits between conductors. 


\subsection{Poka-yoke work station}

Box header 2 (shown in Figure 2) mounted in unique position determined by indexing base

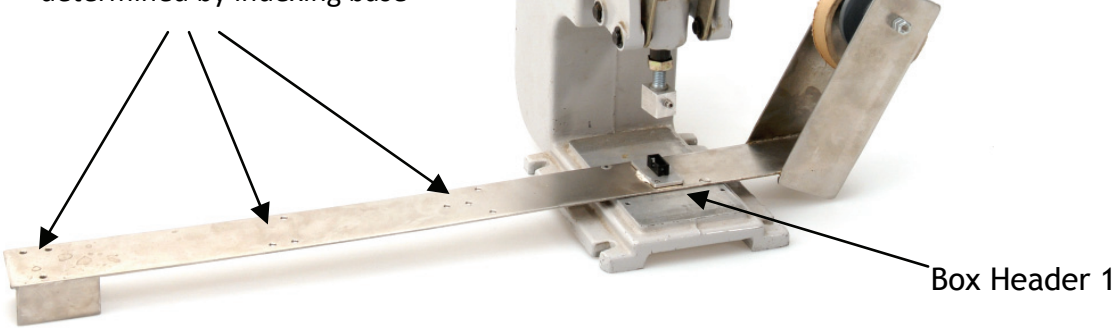

Figure 2: Poka-yoke work station

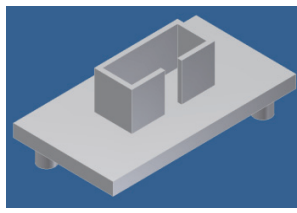

(a) Top view

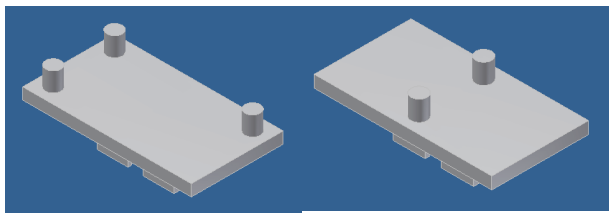

(b) Bottom, config 1

(c) Bottom, config 2

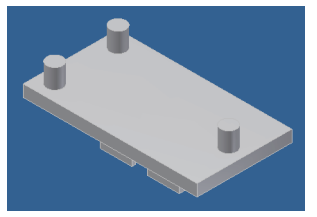

(d) Bottom, config 3

Figure 3: Cable positioning device for length determination, including a number of indexing bases

The work station makes use of an industry standard press for mounting IDC connectors. It is adapted to eliminate assembly errors by means of a Poka-yoke approach.

\subsection{Mistake-proofing using the Poka-yoke approach}

Mistake-proofing the errors that could occur during assembly is described below.

\subsubsection{Socket alignment error: A socket mounted with 180-degree error on the cable}

A keyed socket is used on the cable. The press tool is fitted with a box header that accepts the socket in the correct orientation, as shown in Figure 2. The opening in the 'box' of the box header in Figure 3(a) is identical to the one used to orientate the socket in the press tool. This is an application of a unique location Poka-yoke.

\subsubsection{Socket angular alignment error: $A$ socket mounted with a relatively small angular alignment error on the cable}

The box header 1 (Figure 2) is mounted at 90 degrees to the direction of the cable on the reel. This arrangement causes the first socket to be mounted at a right angle to the cable. The cable is then fed through and positioned in box header 2 . The second socket is press fitted on to the cable in box header 1 . The position and relative alignment of box header 1 and 2 ensures accurate angular alignment of the cable.

\subsubsection{Length of cable error: The cable is cut to the incorrect length}

In the assembly process the first socket is pressed on to the cable while in box header 1 . The cable and socket are then pulled through, and the socket placed in box header 2 , determining the cable length, eliminating measuring. The second socket is then pressed on 
to the cable while in box header 1 . Box header 2 , mounted on an indexing base with a unique pin combination (Figure 3(a)), is located in a set of holes on the jig base corresponding with the length required. Different configurations of the indexing base are shown on the bottom views in Figure 3(b), (c) and (d). It is an application of a unique location Poka-yoke.

\subsubsection{Cable alignment error: Cable conductor 1 is misaligned to socket pin1}

The jig accommodates the cable on a reel. Conductor 1 of a standard ribbon cable is identified with a colour code. A simple instruction on a checklist to mount the cable reel with the colour-coded conductor on a specific side will ensure correct orientation. If the supervisor checks the first cable after a new reel of cable has been fitted, all cables will have the correct orientation. A unique location and checklist Poka-yoke is applied.

\subsubsection{Crimping error: Incorrect operation of the press, omission of the connector locking plate}

If the press is not operated to its bottom limit, the connector blade will not displace the insulation sufficiently to ensure electrical continuity (Figure $1(\mathrm{~b})$ ). If the locking plate of the IDC connector is left out, the cable could be misaligned or insufficiently crimped.

Mistake-proofing mechanism: This problem will not occur if the press lever is operated to the bottom limit. However, the possibility of human error cannot be ruled out. It is possible to construct a press that will mechanically prevent this error. The design of the existing press, however, does not lend itself to the addition of such a feature. To mistake-proof this operation, a simple test jig is used to test whether this operation was executed without error. The test jig is shown in Figure 4. The green LED lights up when all conductors are correctly connected.

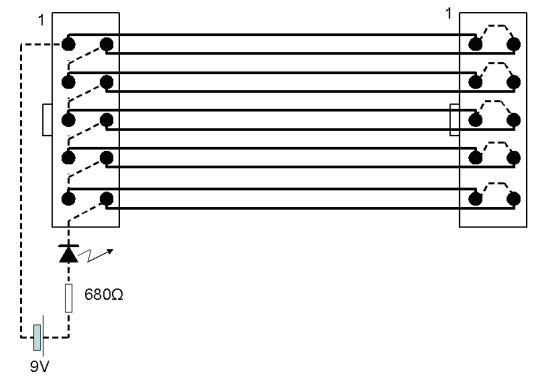

(a) Circuit (test circuit with dotted lines)

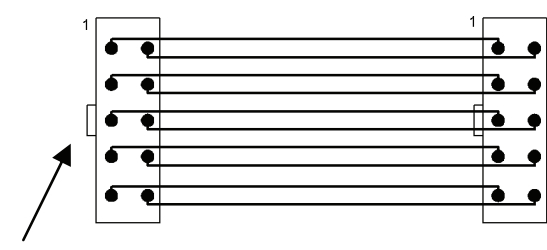

Key corresponding to slot in boxed header shown in Figure 3(a)

(b) Circuit of cable and IDC connectors

Figure 4: Circuit diagram of continuity tester

\subsubsection{Cutting error: Incorrect cutting operation}

This error could be prevented by the use of a guillotine. In the work environment context of workers with disabilities, the use of a guillotine is not considered a safe option. The cable is subjected to a short circuit test using the test jig shown in Figure 5. A short circuit between any two adjacent conductors will cause the current to bypass the LED. The LED will remain off when the cable is inserted, indicating to the worker that the cable is not acceptable, whereas the green light is lit when the cable passes the test. The jig design is such that no current is drawn unless the cable is inserted. This results in a simple test jig, requiring no switches and eliminating the chance of secondary errors. A photograph of the actual test jig that was constructed is shown in Figure 6. 


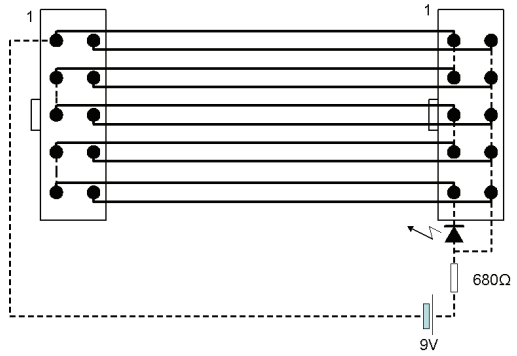

Figure 5: Short circuit testing circuit

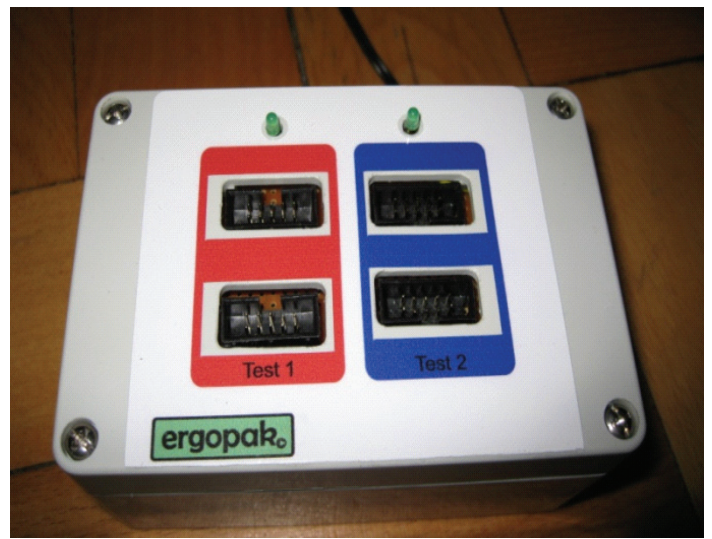

Figure 6: Top view of test apparatus

\section{EXPERIMENTAL METHOD}

For the purpose of data collection, three persons were selected in consultation with the occupational therapist at Horizon House. The candidates were evaluated over a period of three days. Over the evaluation period, 120 cables of four different lengths were assembled. The time taken for assembly was recorded for each cable assembly, providing appropriate feedback, and organising the work environment. Assembly thus took place in a controlled environment under repeatable conditions.

The candidates typically assembled a batch of cables, tested them, and then assembled and tested a second batch. The evaluator handed the candidates the indexing base assembly that determines the length, and instructed them on the number of cables required.

As a base for comparison, the time that a skilled, experienced worker took to perform the task was measured. The time measurement was taken after method optimisation to the worker's skill level and more than 100 repetitions. The measured cycle was normalised with the speed rating technique. Comparison was made on a normalised time basis, i.e. excluding allowances. The comparison is deliberately made with this highest practically attainable task time. The concept of comparison to a 'normal' developing world worker was rejected because of the wide variation in educational level, technological exposure during childhood, and work interest and ethic. To determine the time for a 'normal' job seeker in the developing world would have required a study in its own right, and would have diluted the focus of this study. 


\subsection{Short profile of candidates}

According to the DSM-IV [8], intellectual disability is diagnosed by three main criteria:

i. An IQ score below 70 .

ii. Significant limitations in two or more areas of adaptive behaviour (the ability to function at age-appropriate level in an ordinary environment).

iii. Evidence that the onset of the limitations became apparent during childhood (before the age of 18).

Intellectual disability is formally diagnosed by a professional via an assessment of an individual's intelligence and adaptive behaviour.

The effects of intellectual disability vary in severity, and the following ranges based on the Wechsler Adult Intelligence Scale [9] are in standard use today [10]:

Class IQ

- $\quad$ Below 20 : Profound intellectual disability

- $\quad 20-34$ : Severe intellectual disability

- $\quad 35-49$ : Moderate intellectual disability

- $\quad 50-69$ : Mild intellectual disability

- $\quad 70-79$ : Borderline intellectual disability

Around $85-89 \%$ of all intellectually disabled individuals below the 'borderline' category are mildly intellectually disabled, and can be considered for job placement in manual industrial or office tasks. Intellectually disabled individuals in the 'moderate' category have problems in social awareness, but have fair motor development and can potentially work semiindependently. Intellectually disabled individuals in the 'severe' and 'profound' categories have poor motor development and are not suited to work [7].

\subsubsection{Short profile of Candidate 1}

The candidate is 22 years old. The disability of the candidate is Friedreich's ataxia, resulting in mild intellectual disability. The candidate also requires a hearing aid and uses a wheelchair. The candidate's activities focus on recycling and woodwork.

\subsubsection{Short profile of Candidate 2}

The candidate is 24 years old. The disability of the candidate is Down Syndrome, resulting in rather mild intellectual disability. Tasks at Horizon House include washing, ironing, needlework, beading, sewing-machine operation, and typing.

\subsubsection{Short profile of Candidate 3}

The candidate is 40 years old. The candidate's disability is unspecified, but described as boundary, mild/borderline intellectually disabled. The candidate's activities at Horizon House include needlework, crochet, knitting, beading, dressmaking, and sewing-machine operation.

\section{EXPERIMENTAL RESULTS}

The candidates were assigned the task of assembling cables. The assembly time for each cable was recorded. A learning curve was fitted to the data using the relationship below.

$Y(x)=K x^{n}$ 
where:

$X$ - unit number

$Y(x)$ - Time required to assemble the $x^{\text {th }}$ unit

$\mathrm{K}$ - time to perform the task without any prior learning or experience

$\mathrm{n}-\log \mathrm{b} / \log 2$, where $\mathrm{b}=$ learning percentage

The learning percentage was calculated from:

$\mathrm{b}=10^{\text {nlog2 }}$

As an additional comparative measure, the calculated average time excluded the first ten repetitions of the task to allow for initial learning.

\subsection{Candidate 1}

Candidate 1 experienced considerable difficulty in adapting to the task due to his physical disabilities. He needed to stretch regularly because he sits in a wheelchair. He also struggled to control his hands, and dropped parts on the floor due to the Friedreich's ataxia (which causes uncontrolled motor behaviour). Candidate 1 berated himself when he made mistakes, and easily became distracted. He learned to execute the process with minimal improvement of efficiency over time, as shown in Figure 9.

Using expression 2

$\mathrm{b}=10^{\text {nlog2 }}$,

$\mathrm{n}=-0,0186$ (from the fitted curve in Figure 9)

$\mathrm{b}=0.987$ or $99 \%$

The learning percentage of $99 \%$ indicates that the candidate shows no significant progress or learning in executing the task. The average time for Candidate 1 was 162,2 seconds. This estimate compares well with the learning curve, indicating an expected task time of 163 seconds for the next repetition. The task time is considerably less productive than the 36,5 seconds for a skilled worker.

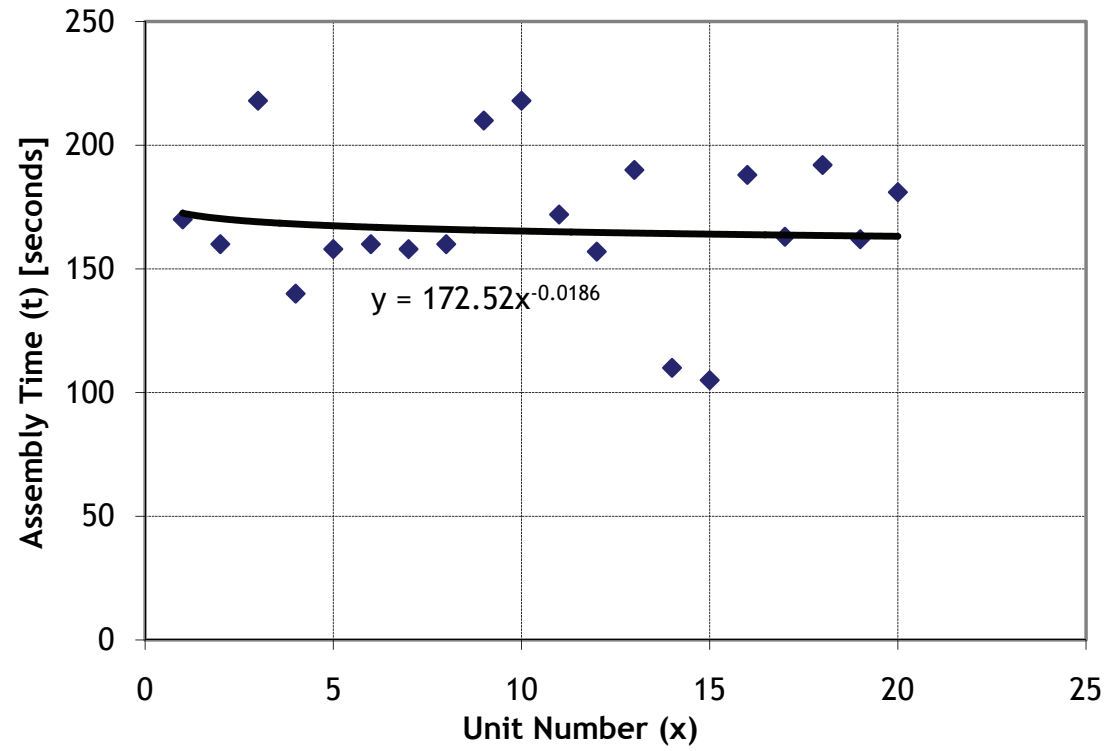

Figure 9: Assembly performance of Candidate 1 


\subsection{Candidate 2}

Candidate 2 kept a relatively constant working pace, and learned to do the process a little faster with experience, but never rushed herself. Candidate 2 needed no second explanation for the second assembly run, showed no signs of tiring or discomfort, and responded positively to feedback from the evaluator. Candidate 2 adapted very well to the task and displayed a significant learning trend.

Using expression 2

$\mathrm{b}=10^{\text {nlog2 }}$,

$\mathrm{n}=-0,137$ (from the fitted curve in Figure 10)

b $=0.909$ or $91 \%$

The calculated learning percentage of $91 \%$ indicates that the candidate improved significantly as experience of the task was gained. It is in the same order of magnitude as the learning percentage of $95 \%$, which is considered to be an industry norm for electronic assembly [12]. The average time for Candidate 2 was 50,2 seconds. The projected task time from the learning curve indicates a task time of 46,1 seconds for the next repetition. The projected task time is considered within the limits of $\pm 40 \%$ variability among average workers compared to the $36,5( \pm 14,6)$ seconds for a skilled worker [13].

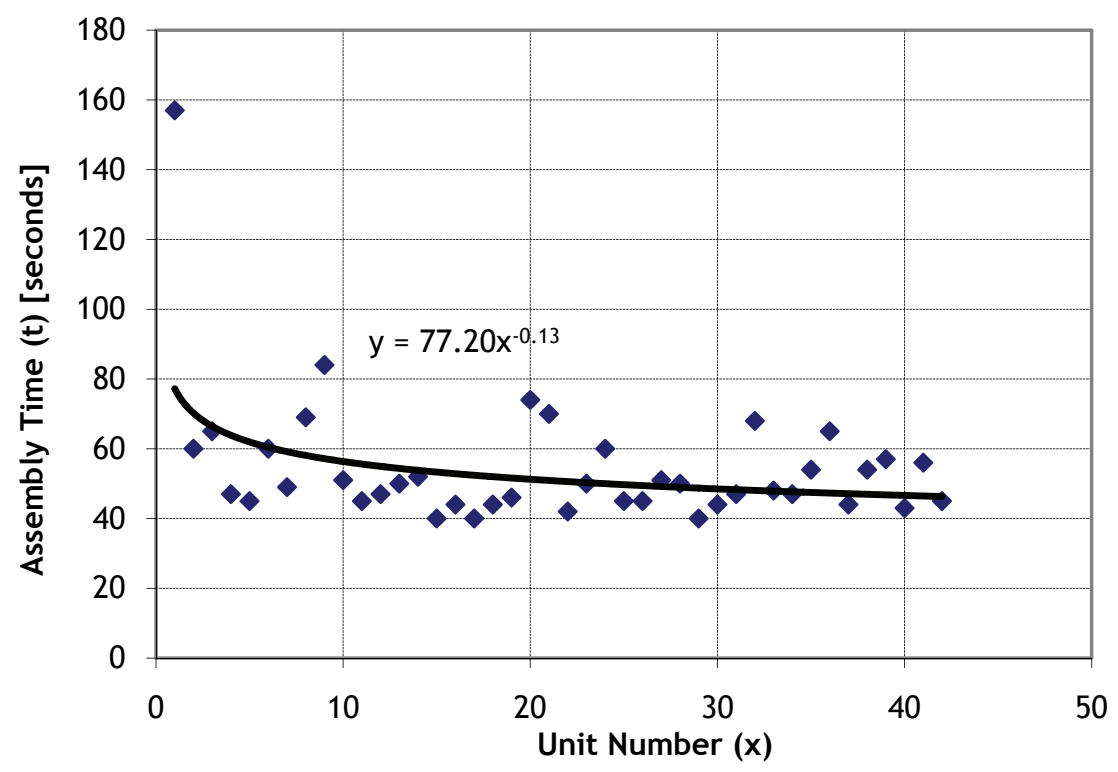

Figure 10: Assembly performance of Candidate 2

\subsection{Candidate 3}

Although Candidate 3 had the fastest time for the assembly of some cables, her average time was slower than the average of candidate 2 because she was not as consistent and methodical as Candidate 2. She showed improvement by learning to do the process more efficiently with time, and did not need to be reminded how to execute the process on the second assembly run. Candidate 3 often placed the second IDC in box header 2 (Figure 3(a)) holder and not in clamping holder (Header \#1), but was able to correct herself each time due to the mistake-proofing design of the jig. Candidate 3 also had trouble orientating the IDCs in the jig (180 degree placement error) and test apparatus, but corrected herself each time because the jig did not accept the IDC socket in an erroneous orientation, visibly demonstrating the success of the Poka-yoke approach. 
Using expression 2

$\mathrm{b}=10^{\text {nlog2 }}$,

$\mathrm{n}=-0,2429$ (from the fitted curve in Figure 11)

$\mathrm{b}=0.845$ or $85 \%$

The learning percentage of $85 \%$ calculated from the fitted curve indicates that the candidate improved rather well with experience. It should also be seen against the background of rather difficult adaption at first, as indicated by slow initial times. It is higher than the learning percentage of $95 \%$ that is usual for electronic assembly [12]. This is not considered as significant, as the candidate could have learnt skills that a member of the broader population has already learnt through normal functioning. The average time for Candidate 3 was 53,2 seconds. The projected task time from the learning curve indicates a task time of 43,1 seconds for the next repetition. The projected task time is within the limits of $\pm 40 \%$ variability among average workers compared to the $36,5( \pm 14,6)$ seconds for a skilled worker [13].

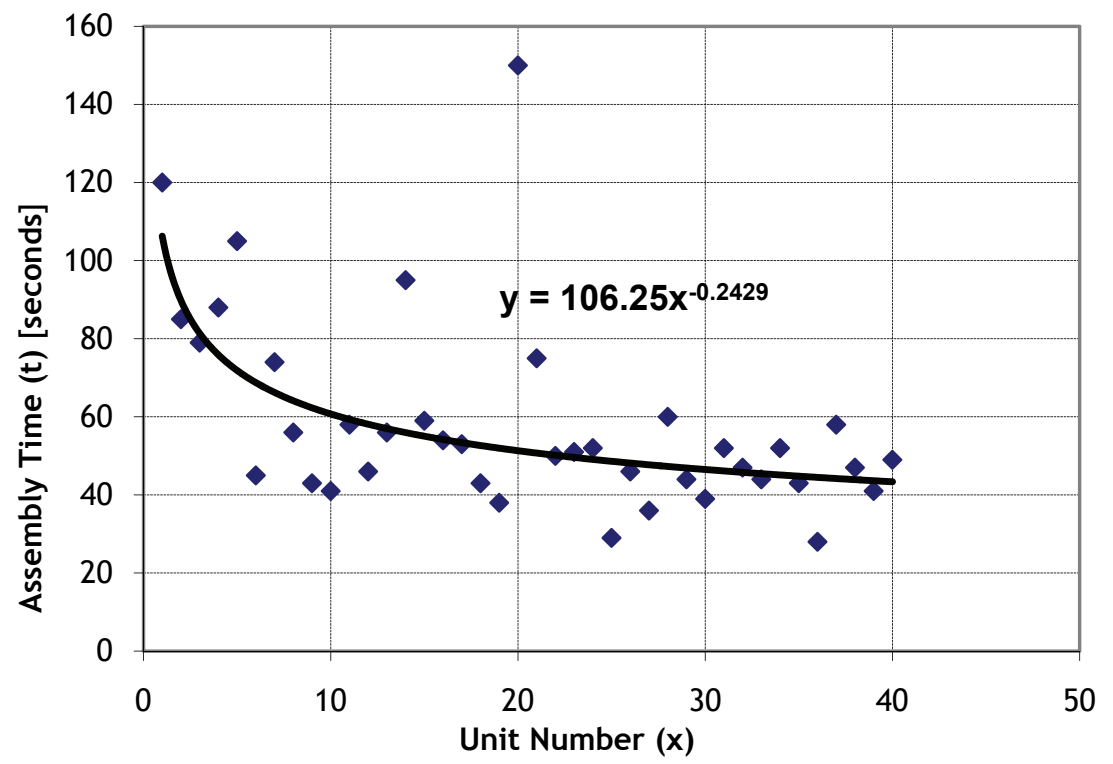

Figure 11: Assembly performance of Candidate 3

\subsection{Assessment}

Candidate 1 was not suitable for the assembly work due to his physical attributes. His large hands were not suited to fine assembly work, and this was exacerbated by the Friedreich's ataxia. He could, however, do the work with concentration. The errors that prompted the assessment that this candidate is not suitable are based on physical limitations. The complexity level of the Poka-yoke designed process was well within his reach.

Candidate 2 performed satisfactorily and consistently. She concentrated and focused well, and rarely if ever got distracted. A crucial part of this candidate's success can be attributed to the Poka-yoke initiated, structured nature of the work. The low uncertainty level and low possibility of making a mistake reduced the stress level of the work and resulted in a self-assured work style.

Candidate 3 was confident and performed the work effectively. She made occasional mistakes, but was able to correct herself due to the Poka-yoke. For example, when an IDC socket was inserted in the wrong orientation, the socket did not fit. This prompted repositioning for a correct fit. 


\section{CONCLUSION}

The assessment of the candidates' work showed that all the candidates fully understood the process and what was expected of them. Therefore the reduction of the mental workload to an acceptable level by the Poka-yoke approach is considered to have been successful.

Two of the candidates achieved a productivity level comparable to that of a skilled worker. The third worker could not be accommodated in such a way that productive work could be achieved; the predominant constraints were physical - e.g. his being bound to a wheelchair, and his inability to handle small components. There were positive indications that the mental workload of the work station using Poka-yoke principles were within the reach of the individual.

In this study, a typical developed world electronic manufacturing task, ribbon cable assembly, was adapted for execution by intellectually disabled individuals. The work station was designed using the Poka-yoke approach. It was proved that productive work can be performed by a section of the population of intellectually disabled individuals when the Poka-yoke approach is used to mistake-proof the processes. It was also shown that some individuals that are intellectually disabled may not possess the capability to perform productive work, even though the work process is mistake-proofed, making selection desirable.

It is therefore concluded that the employment potential of mentally disabled workers in advanced technology production can be improved by work station design employing the Poka-yoke approach. In this way meaningful employment can be offered to disabled individuals that could enable them to play a respected role in society and simultaneously enhance their self image.

\section{REFERENCES}

[1] Census 2001. Prevalence of disability in South Africa. Report -03-02-44, Statistics South Africa.

[2] Poulton, E.C. 1966. Engineering psychology. Annual Review of Psychology, 17, 177200

[3] Wickens, C.D. \& Hollands, J.G. Engineering psychology and human performance. 3rd ed., Prentice-Hall, New Jersey, 2000.

[4] Hradesky, J.H. 1995. Total quality management handbook. McGraw-Hill, New York.

[5] Shingo, S. 1981. Study of 'TOYOTA' production system from industrial engineering viewpoint. Japan Management Association, Tokyo.

[6] Nikkan, K.S. 1988. Poka-yoke improving product quality by preventing defects. Productivity Press, Cambridge, MA.

[7] Salvendy, G. (ed.). 1982. Handbook of industrial engineering. John Wiley and Sons, New York.

[8] Diagnostic and Statistical Manual of Mental Disorders. Fourth edition (DSM-IV), [Online], Available from http://allpsych.com/disorders/dsm.html

[9] Wechsler adult intelligence scale. [Online] Available from http://www.minddisorders.com/Py-Z/Wechsler-adult-intelligence-scale.html

[10] Intellectual disability - core information. [Online] Available from http://www.openroad.net.au/access/dakit/intellectual/inhandout1.htm

[11] Intellectual disability - facts and figures. [Online] Available from http://www.betterhealth.vic.gov.au/bhcv2/bhcArticles.nsf/pages/Intellectual_disa bility_facts_and_figures? OpenDocument

[12] Konz, S.A. \& Johnson, S. 2000. Work design: Industrial ergonomics, 5th ed., Holcomb Hathaway, Arizona.

[13] Niebel, B.W. \& Freivalds, A. 2004. Methods, standards, and work design. 11th ed., McGraw-Hill, New York. 